\title{
Azonexus hydrophilus sp. nov., a nifH gene-harbouring bacterium isolated from freshwater
}

\author{
Correspondence \\ Wen-Ming Chen \\ p62365@ms28.hinet.net
}

\author{
Jui-Hsing Chou, ${ }^{1}$ Sing-Rong Jiang, ${ }^{2}$ Jang-Cheon Cho, ${ }^{3}$ Jaeho Song, ${ }^{3}$ \\ Mei-Chun Lin ${ }^{2}$ and Wen-Ming Chen ${ }^{2}$ \\ ${ }^{1}$ Department of Soil and Environmental Sciences, College of Agriculture and Natural Resources, \\ National Chung Hsing University, Taichung, Taiwan \\ ${ }^{2}$ Laboratory of Microbiology, Department of Seafood Science, National Kaohsiung Marine \\ University, No. 142, Hai-Chuan Rd, Nan-Tzu, Kaohsiung City 811, Taiwan \\ ${ }^{3}$ Division of Biology and Ocean Sciences, Inha University, Yonghyun Dong, Incheon 402-751, \\ Republic of Korea
}

The genus Azonexus, proposed by Reinhold-Hurek \& Hurek (2000), currently comprises two bacterial species with validly published names, Azonexus fungiphilus and Azonexus caeni. The genus Azonexus is a member of the family Rhodocyclaceae in the class Betaproteobacteria and encompasses Gram-negative, non-spore-forming, highly motile and slightly curved rods. A. fungiphilus, formerly named Azoarcus sp. group E, was isolated from the resting stage of a plant-associated basidiomycete in the rhizosphere soil (Hurek et al., 1997) and A. caeni is a

The GenBank/EMBL/DDBJ accession numbers for the 16S rRNA gene sequences of strains $\mathrm{d} 8-1^{\top}$, d8-2 and IMCC1716 are EF158390, EF158391 and DQ664239, respectively. Those for the partial nifH gene sequences of strains $\mathrm{d} 8-1^{\top}$, d8-2 and IMCC1716 are EF626684, EF626685 and EF626686, respectively.

An electron micrograph of strain $d 8-1^{\top}$ (Fig. S1) and a nifH gene sequence-based phylogenetic tree comprising the novel strains and related species (Fig. S2) are available with the online version of this paper. denitrifying bacterium isolated from sludge of a wastewater treatment plant (Quan et al., 2006). This study focuses on the taxonomic study of three Azonexus-like strains isolated from two different freshwater environments. Based on a polyphasic taxonomic investigation, the three strains represent a novel species in the genus Azonexus.

Two bacterial strains ( $\mathrm{d} 8-1^{\mathrm{T}}$ and $\left.\mathrm{d} 8-2\right)$ were isolated from a water sample collected from a freshwater spring located in Hsinchu County, Taiwan, on tryptic soy agar (BD Difco) at $35{ }^{\circ} \mathrm{C}$. Strain IMCC1716 was isolated from a eutrophic freshwater pond located at Inha University, Korea, on R2A agar (BD Difco) at $25{ }^{\circ} \mathrm{C}$. The isolates were routinely maintained on tryptic soy broth (BD Difco) or R2A agar at $35^{\circ} \mathrm{C}$. A. fungiphilus $\mathrm{BS} 5-8^{\mathrm{T}}$ and A. caeni Slu- $05^{\mathrm{T}}$, obtained from the Korean Collection for Type Cultures, Yusong, Taejon, Republic of Korea, were used as reference strains. The morphology of bacterial cells was observed during the lag, exponential and stationary phases of growth under a phase-contrast microscope (DM2000; Leica) and by 
scanning electron microscopy (S-3500N; Hitachi). Flagellar staining was performed using the Spot Test Flagella stain (BD Difco). The Gram reaction was performed using the Gram Stain set (BD Difco) and the Ryu non-staining $\mathrm{KOH}$ method (Powers, 1995). Accumulation of poly- $\beta$-hydroxybutyrate granules was observed by light microscopy after staining cells with Sudan black (Gerhardt et al., 1994). Colony morphology was examined using a stereoscopic microscope (SMZ800; Nikon) after incubating the cells on $\mathrm{R} 2 \mathrm{~A}$ agar at $30{ }^{\circ} \mathrm{C}$ for 2 days. The optimum $\mathrm{pH}$ range for growth was examined by measuring $\mathrm{OD}_{595}$ of the cultures grown in nutrient broth (BD Difco) adjusted to various $\mathrm{pH}$ values ( $\mathrm{pH} 4-10$ at intervals of $1.0 \mathrm{pH}$ unit) using appropriate biological buffers (Chung et al., 1995). The $\mathrm{NaCl}$ tolerance range of the strains was tested in nutrient broth adjusted to various $\mathrm{NaCl}$ concentrations $(0,0.5$ and $1.0-4.0 \%, \mathrm{w} / \mathrm{v}$, at $1.0 \%$ intervals). The temperature range for growth $\left(4,10,15,20,25,30,35,40\right.$ and $\left.45{ }^{\circ} \mathrm{C}\right)$ was examined in nutrient broth. Anaerobic cultivation was performed on R2A agar using the Oxoid AnaeroGen system. For the nitrogenase activity test, the three strains were inoculated in $33 \mathrm{ml}$ rubber-septa-sealed vials containing $10 \mathrm{ml}$ semi-solid nitrogen-free medium [DSMZ medium no. 3 or nitrogen-free SM medium (Reinhold et al., 1986)] and incubated in the dark at $35^{\circ} \mathrm{C}$. After $48-$ $240 \mathrm{~h}$ of incubation, $10-50 \%(\mathrm{v} / \mathrm{v})$ of the air phase was replaced by acetylene. Nitrogen-fixing ability was determined using the acetylene reduction assay as described by Elliott et al. (2007). Catalase, oxidase, DNase, arginine dihydrolase, urease and lipase activities, nitrate reduction and hydrolysis of starch, casein and Tweens 20, 40, 60 and 80 were determined using standard methods (Gerhardt et al., 1994; Lanyi, 1987; MacFaddin, 2000). Additional biochemical tests were performed using the API 20NE (bioMérieux), API ZYM (bioMérieux) and Biolog GN2 (Biolog) microtest systems according to the methods outlined by the manufacturers. Eleven different kinds of antimicrobial agent (listed in Table 1) were tested by the

\section{Table 1. Differential biochemical characteristics of Azonexus species}

All data were acquired in the present study, except for the DNA G + C content of A. caeni (Quan et al., 2006). +, Positive; -, negative; R, resistant; $\mathrm{S}$, sensitive; V, variable; ND, no data available. Data in parentheses for A. hydrophilus are for the type strain $\left(\mathrm{d} 8-1^{\mathrm{T}}\right)$. All strains have the following features: positive for the oxidation of Tween 40 , Tween $80, \beta$-hydroxybutyric acid, DL-lactic acid, propionic acid, succinic acid and L-glutamic acid; negative for the oxidation of $\alpha$-cyclodextrin, dextrin, glycogen, $N$-acetyl-D-galactosamine, $N$-acetyl-D-glucosamine, adonitol, L-arabinose, Darabitol, cellobiose, i-erythritol, D-fructose, L-fucose, D-galactose, gentiobiose, $\alpha$-D-glucose, myo-inositol, $\alpha$-D-lactose, lactulose, maltose, Dmannitol, D-mannose, melibiose, methyl $\beta$-D-glucoside, D-psicose, raffinose, L-rhamnose, D-sorbitol, sucrose, trehalose, turanose, xylitol, succinic acid monomethyl ester, acetic acid, citric acid, formic acid, D-galacturonic acid, D-gluconic acid, D-glucosaminic acid, D-glucuronic acid, $\alpha$ hydroxybutyric acid, $\gamma$-hydroxybutyric acid, $p$-hydroxyphenylacetic acid, $\alpha$-ketobutyric acid, $\alpha$-ketovaleric acid, malonic acid, quinic acid, Dsaccharic acid, sebacic acid, L-alaninamide, glycyl-L-glutamic acid, L-histidine, hydroxy-L-proline, L-leucine, L-ornithine, D-serine, L-serine, Lthreonine, $\gamma$-aminobutyric acid, urocanic acid, inosine, uridine, thymidine, phenylethylamine, putrescine, 2-aminoethanol, 2,3-butanediol, glycerol, DL- $\alpha$-glycerol phosphate, $\alpha$-D-glucose 1-phosphate, D-glucose 6-phosphate, glucuronamide, D-alanine, L-alanine, L-alanyl glycine, D-galactonic acid lactone, DL-carnitine, L-phenylalanine, glycyl-L-aspartic acid, and glucosidase and galactosidase activities. All strains are sensitive to ampicillin $(10 \mu \mathrm{g})$, chloramphenicol $(30 \mu \mathrm{g})$, erythromycin $(15 \mu \mathrm{g})$, gentamicin $(10 \mu \mathrm{g})$, kanamycin $(30 \mu \mathrm{g})$, nalidixic acid $(30 \mu \mathrm{g})$, novobiocin $(30 \mu \mathrm{g})$, penicillin $\mathrm{G}(10 \mathrm{U})$, streptomycin $(10 \mu \mathrm{g})$ and tetracycline $(30 \mu \mathrm{g})$.

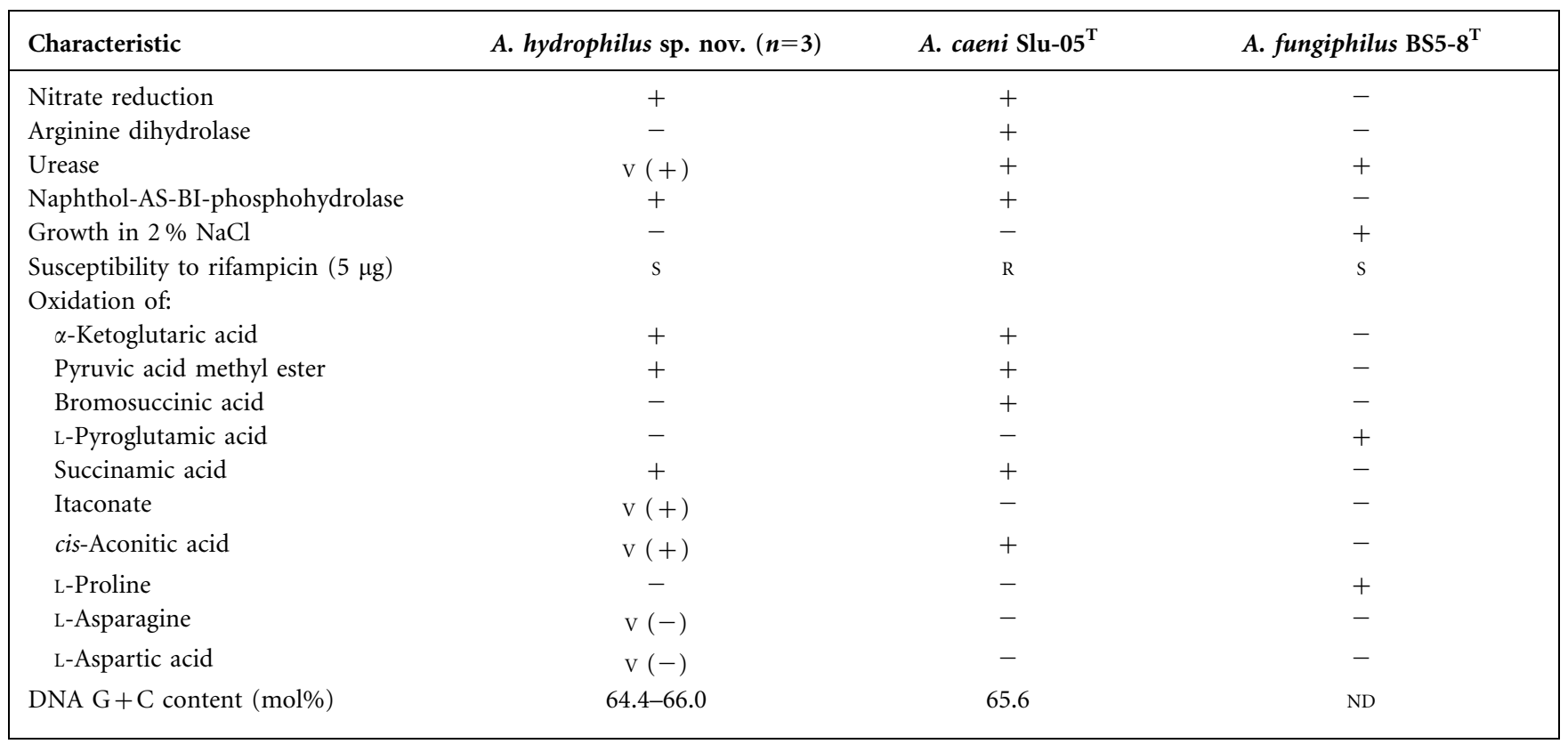


diffusion method on Mueller-Hinton agar (BD Difco). The effect of antimicrobial agents on cellular growth was assessed after 3 days of incubation and susceptibility was scored based on the distance between the edges of the clear zone and the disc.

Detailed morphological, physiological and biochemical characteristics of strains $\mathrm{d} 8-\mathrm{1}^{\mathrm{T}}, \mathrm{d} 8-2$ and IMCC1716 are provided in the species description, Table 1 and Supplementary Fig. S1 (available with the online version of this paper). Cells were Gram-negative, facultatively aerobic, non-spore-forming, slightly curved rods that were motile by a single polar flagellum. A comparison of biochemical characteristics of the three novel strains and those of the type strains of species of the genus Azonexus is presented in Table 1. Strains $\mathrm{d} 8-1^{\mathrm{T}}$, d8-2 and IMCC1716 did not grow in nitrogen-free DSMZ medium no. 3 supplemented with glucose or mannitol as sole carbon sources. In contrast, the three strains grew well in nitrogenfree SM medium supplemented with malate as sole carbon source. However, nitrogen-fixing activity was not observed in the acetylene reduction assay.

Extraction of genomic DNA, PCR amplification and sequencing of the $16 \mathrm{~S}$ rRNA gene were carried out as described by Chen et al. (2001). The potential for nitrogen fixation was examined by amplifying the nifH gene using the nifH3 and nifH4 primer set, as described by Zani et al. (2000). The resultant $16 \mathrm{~S}$ rRNA gene and nifH gene sequences were compared with sequences available from
GenBank. Multiple sequence alignments of the genes of strains $\mathrm{d} 8-1^{\mathrm{T}}, \mathrm{d} 8-2$, IMCC1716 and their closest relatives were performed using BIOEDIT (Hall, 1999) and MEGA version 3.1 (Kumar et al., 2004) software. Phylogenetic trees were inferred using the maximum-likelihood (Felsenstein, 1981), maximum-parsimony (Kluge \& Farris, 1969) and neighbour-joining (Saitou \& Nei, 1987) algorithms. Evolutionary distance matrixes were generated for the neighbour-joining tree using the Kimura twoparameter distance model (Kimura, 1983) and bootstrap analysis was performed based on 1000 resamplings.

Nearly complete $16 \mathrm{~S}$ rRNA gene sequences were obtained for strains $\mathrm{d} 8-1^{\mathrm{T}}, \mathrm{d} 8-2$ and IMCC1716 (1454, 1464 and $1488 \mathrm{nt}$, respectively). The $16 \mathrm{~S}$ rRNA gene sequence similarities between the strains were 99.6-99.7\%. The three strains were most closely related to A. caeni Slu- $05^{\mathrm{T}}$ (96.7-96.8\% similarity) and A. fungiphilus BS5-8 ${ }^{\mathrm{T}}$ (96.3$96.6 \%$ similarity). Phylogenetic analysis based on $16 \mathrm{~S}$ rRNA gene sequences indicated that the strains belonged to the family Rhodocyclaceae of the class Betaproteobacteria and fell within the evolutionary radiation of the genus Azonexus (Fig. 1). No other species in the class Betaproteobacteria with validly published names showed more than $96 \% 16 \mathrm{~S}$ rRNA gene sequence similarity. The overall tree topologies obtained from neighbour-joining, maximum-parsimony and maximum-likelihood methods were similar (data not shown). Because the nifH gene phylogeny of diazotrophic bacteria has been reported to generally correlate well with the $16 \mathrm{~S}$ rRNA gene phylogeny

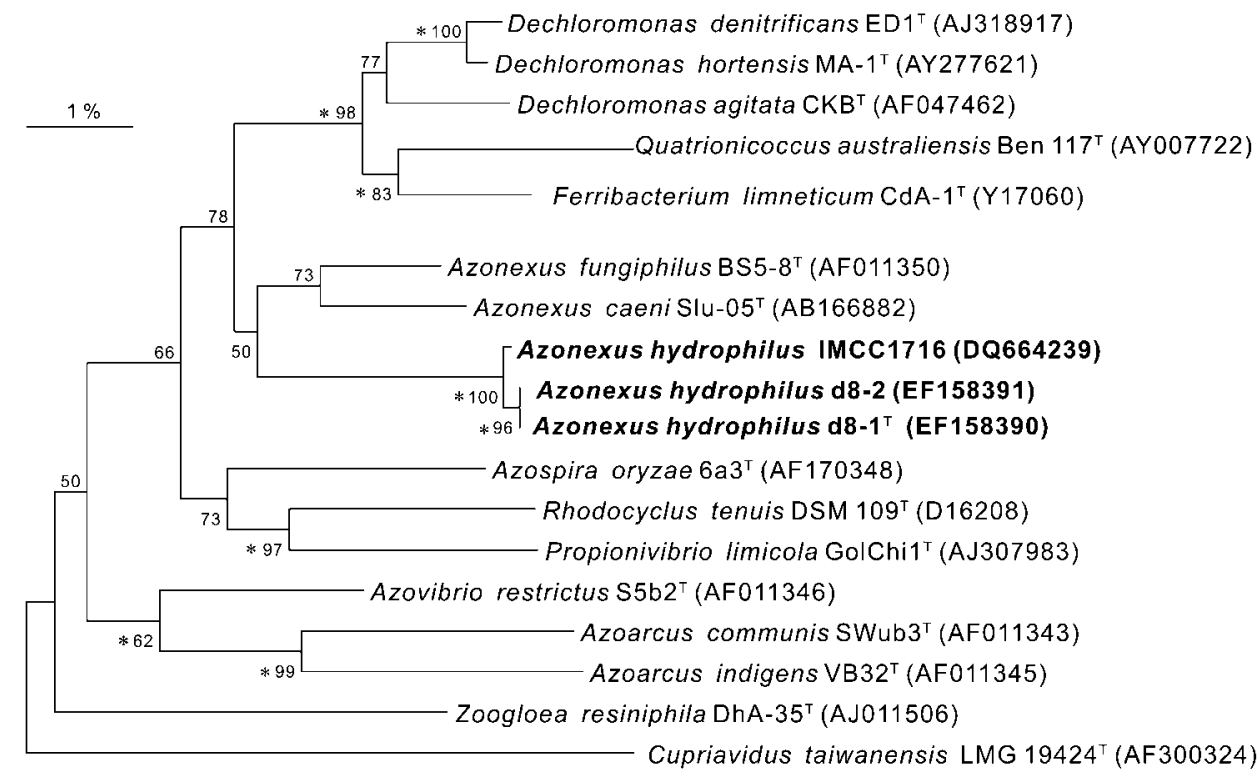

Fig. 1. Phylogenetic tree based on $16 \mathrm{~S}$ rRNA gene sequences showing the relationships between strains $d 8-1^{\top}$, d8-2 and IMCC1716 and related taxa in the class Betaproteobacteria. The neighbour-joining method was employed with the Kimura twoparameter model. Numbers at nodes are percentages of bootstrap values based on 1000 resamplings; only values above $50 \%$ are shown. Asterisks indicate branches that were recovered using the maximum-parsimony algorithm. Bar, $1 \%$ sequence dissimilarity. The sequence of Cupriavidus taiwanensis LMG $19424^{\top}$ was used as an outgroup. 
(Chen et al., 2003; Moulin et al., 2001; Rosado et al., 1998; Xie \& Yokota, 2004; Young, 1992), the nifH gene was selected as another marker to elucidate phylogenetic relationships for the three novel strains and related taxa. The nifH gene sequence similarities between strains $\mathrm{d} 8-1^{\mathrm{T}}$, d8-2 and IMCC1716 were 99.0-100\%. The strains showed 95.7-96.1\% and $92.2 \%$ nifH gene sequence similarities to $A$. fungiphilus and A. caeni, respectively. A phylogenetic tree based on nifH gene sequences also showed the monophyletic relationship between the three novel freshwater isolates and related species of the genus Azonexus (see Supplementary Fig. S2 in the online version of this paper).

Whole genome DNA-DNA hybridization experiments were performed with photobiotin-labelled probes as described by Ezaki et al. (1989). The degree of DNADNA relatedness was calculated from triplicate experiments. The DNA-DNA relatedness values between strains $\mathrm{d} 8-1^{\mathrm{T}}, \mathrm{d} 8-2$ and IMCC1716 were $89-100 \%$, indicating that the three strains are members of the same genomic species (Wayne et al., 1987). Strain $\mathrm{d} 8-1^{\mathrm{T}}$ showed $45 \pm 7 \%$ and $22 \pm 10 \%$ DNA-DNA relatedness with A. caeni Slu- $05^{\mathrm{T}}$ and $A$. fungiphilus $\mathrm{BS} 5-8^{\mathrm{T}}$, respectively.

For chemotaxonomic analyses, all of the strains employed for the analyses were grown on R2A agar for 3 days at $30{ }^{\circ} \mathrm{C}$. Fatty acid methyl esters were prepared, separated and identified according to the instructions of the Microbial Identification system (Microbial ID; Sasser, 1990). Polar lipids were extracted and analysed by twodimensional TLC according to Embley \& Wait (1994). The DNA $\mathrm{G}+\mathrm{C}$ content was determined in triplicate by HPLC as described by Mesbah et al. (1989). Preparation of wholecell proteins and SDS-PAGE were performed as described by Pot et al. (1994). Electrophoretic protein patterns were recorded on an Astra 1220 S scanner (Umax Systems). Bands with migration differences of less than $3 \%$ were considered to be the same band. Normalization of the protein profiles and clustering by UPGMA were performed with Universal Software 1D Advanced (Advanced American Biotechnology and Imaging).

The major cellular fatty acid constituents of strain $\mathrm{d} 8-1^{\mathrm{T}}$ were $\mathrm{C}_{16: 0}(28.2 \%), \mathrm{C}_{16: 1} \omega 7 c(48.1 \%)$ and $\mathrm{C}_{18: 1}$ isomers $(13.0 \%)$ (Table 2). The overall cellular fatty acid profiles of strain $\mathrm{d} 8-1^{\mathrm{T}}$ were generally in accordance with those of the two recognized species of the genus Azonexus. However, strain $\mathrm{d} 8-1^{\mathrm{T}}$ could be differentiated from the type strains of A. fungiphilus and A. caeni by the absence of $\mathrm{C}_{12: 0} 3-\mathrm{OH}$, $\mathrm{C}_{15: 0}$ and $\mathrm{C}_{17: 1} \omega 6 c$ and the presence of $\mathrm{C}_{19: 1} \omega 6 c$ (Table 2). The predominant polar lipids of strain $\mathrm{d} 8-1^{\mathrm{T}}$ were phosphatidylethanolamine, phosphatidylglycerol and diphosphatidylglycerol. The DNA G $+\mathrm{C}$ contents of strains $\mathrm{d} 8-1^{\mathrm{T}}, \mathrm{d} 8-2$ and IMCC1716 were $66.0 \pm 0.5,66.0 \pm 1.0$ and $64.4 \pm 1.0 \mathrm{~mol} \%$, respectively; these were similar to the DNA G + C content of A. caeni (65.6 mol\%; Table 1 ). When the whole-cell protein profiles of the three freshwater isolates were compared with those of the type strains of $A$. fungiphilus and A. caeni, the three novel strains formed a single cluster with similarities of $>93 \%$, but showed less than $83 \%$ similarity to the two Azonexus species (Fig. 2). These results further confirm the separate taxonomic position of strains $\mathrm{d} 8-1^{\mathrm{T}}$, d8-2 and IMCC1716 within the genus Azonexus.

Based on $16 \mathrm{~S}$ rRNA and nifH gene sequence comparisons, strains $\mathrm{d} 8-\mathrm{1}^{\mathrm{T}}, \mathrm{d} 8-2$ and IMCC1716 occupied a separate phylogenetic position in the genus Azonexus. This was

Table 2. Fatty acid content (\%) of Azonexus hydrophilus sp. nov. and the type strains of two Azonexus species

Data for A. caeni Slu- $05^{\mathrm{T}}$ and A. fungiphilus $\mathrm{BS} 5-8^{\mathrm{T}}$ are from Quan et al. (2006). Strains $\mathrm{d} 8-1^{\mathrm{T}}$, d8-2 and IMCC1716 were cultured on R2A agar (BD Difco) at $30{ }^{\circ} \mathrm{C}$, the same culture conditions as reported for $A$. fungiphilus $\mathrm{BS} 5-8^{\mathrm{T}}$ and A. caeni Slu- $05^{\mathrm{T}}$. - Not detected. Data in parentheses for A. hydrophilus are for the type strain $\left(\mathrm{d} 8-1^{\mathrm{T}}\right)$.

\begin{tabular}{|lccc|}
\hline Fatty acid & A. hydrophilus sp. nov. $(\boldsymbol{n}=\mathbf{3})$ & A. $_{\text {caeni Slu-05 }}{ }^{\mathrm{T}}$ & A. fungiphilus $^{\text {BS5-8 }} \mathbf{8}^{\mathbf{T}}$ \\
\hline Straight-chain fatty acids: & & & \\
$12: 0$ & $2.0-3.0(3.0)$ & 2.9 & 2.7 \\
$14: 0$ & $1.0-1.8(1.0)$ & 1.6 & 2.1 \\
$15: 0$ & $-(-)$ & 1.2 & 2.5 \\
$16: 0$ & $25.2-29.4(28.2)$ & 19.3 & 16.7 \\
$18: 0$ & $0.3-1.0(0.7)$ & 1.1 & 3.5 \\
Unsaturated fatty acids: & & & \\
$16: 1 \omega 7 c$ & $44.4-48.1(48.1)$ & 48.0 & 40.5 \\
$17: 1 \omega 6 c$ & $-(-)$ & 18.8 & 1.0 \\
$18: 1$ isomers & $11.3-17.2(13.0)$ & - & - \\
$19: 1 \omega 6 c$ & $0.5-1.8(1.7)$ & & \\
Hydroxy fatty acids: & $4.4-5.4(4.6)$ & 5.4 & 4.1 \\
$10: 03-\mathrm{OH}$ & $-(-)$ & 1.1 & 0.7 \\
$12: 03-\mathrm{OH}$ & & & \\
\hline
\end{tabular}




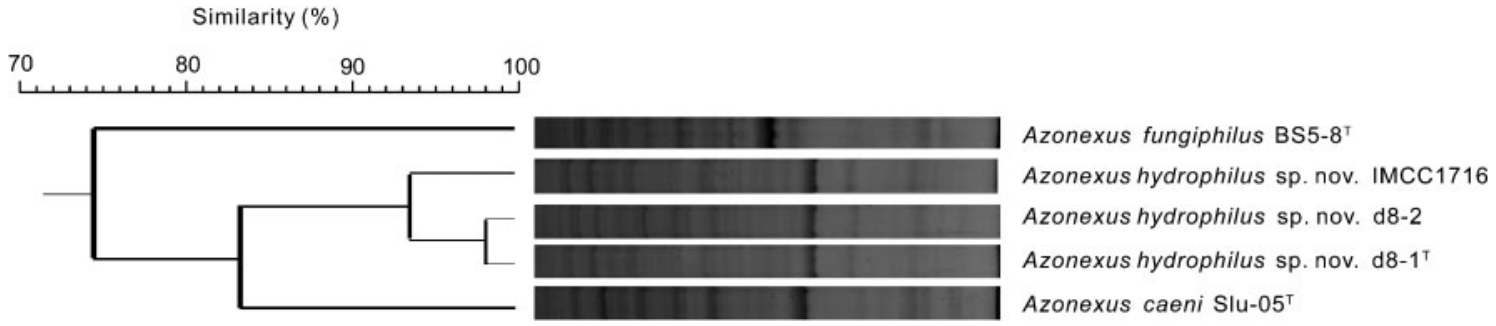

Fig. 2. Dendrogram based on numerical analysis of the whole-cell protein profiles of strains $d 8-1^{\top}$, d8-2 and IMCC 1716 and the type strains of two closely related Azonexus species.

confirmed by their unique combination of chemotaxonomic characteristics (Tables 1 and 2; Fig. 2) and biochemical traits (Table 1). It is clear from the genotypic and phenotypic data that strains $\mathrm{d} 8-\mathrm{1}^{\mathrm{T}}, \mathrm{d} 8 \mathrm{-2}$ and IMCC1716 represent a novel species in the genus Azonexus for which the name Azonexus hydrophilus sp. nov. is proposed.

\section{Description of Azonexus hydrophilus sp. nov.}

Azonexus hydrophilus [hy.dro'phi.lus. Gr. n. hudor (or hydor) water; Gr. adj. philos loving; N.L. masc. adj. hydrophilus water-loving, referring to its source of isolation].

Cells are Gram-negative, non-spore-forming, slightly curved rods $(0.3-0.5 \mu \mathrm{m}$ in diameter and 1.1-2.2 $\mu \mathrm{m}$ in length), motile by means of a single polar flagellum. Colonies on R2A agar are round with umbonate elevation and semi-transparent with irregular edges. Colonies are approximately $0.3-0.6 \mathrm{~mm}$ in diameter on R2A agar after $48 \mathrm{~h}$ incubation at $35{ }^{\circ} \mathrm{C}$. Optimum growth occurs at 35 $40{ }^{\circ} \mathrm{C}, 0-1 \% \mathrm{NaCl}$ and $\mathrm{pH} \mathrm{7.0-8.0.} \mathrm{Cells} \mathrm{grow} \mathrm{under}$ anaerobic conditions, but growth is weaker than under aerobic conditions. Positive for catalase, cytochrome oxidase, and hydrolysis of starch (weak), Tween 40 and Tween 60. Negative for DNase, lipase (corn oil) and hydrolysis of skimmed milk and Tween 20. In API 20NE tests, positive for nitrate reduction and malate assimilation and negative for indole production, arginine dihydrolase, aesculin hydrolysis, gelatinase, $\beta$-galactosidase and assimilation of glucose, arabinose, mannose, mannitol, $N$ acetylglucosamine, maltose, caprate, adipate, citrate and phenylacetate. Urease and gluconate assimilation are strain-dependent. Positive (API ZYM) for alkaline phosphatase, C4 esterase, C8 lipase, leucine arylamidase and naphthol-AS-BI-phosphohydrolase, but negative for C14 lipase, valine arylamidase, cystine arylamidase, trypsin, $\alpha-$ chymotrypsin, acid phosphatase, $\alpha$-galactosidase, $\beta$-galactosidase, $\alpha$-glucosidase, $\beta$-glucosidase, $\beta$-glucuronidase, $N$ acetyl- $\beta$-glucosaminidase, $\alpha$-mannosidase and $\alpha$-fucosidase. Acid phosphatase activity is strain-dependent. The results for carbon source oxidation and antimicrobial susceptibility tests are presented in Table 1. Oxidation of the following compounds is strain-dependent: itaconic acid, cis-aconitic acid, L-asparagine and L-aspartic acid. The major cellular fatty acids are $\mathrm{C}_{16: 0}, \mathrm{C}_{16: 1} \omega 7 c$ and $\mathrm{C}_{18: 1}$ isomers. The predominant polar lipids are phosphatidylethanolamine, phosphatidylglycerol and diphosphatidylglycerol. The DNA G + C content is $64-66 \mathrm{~mol} \%$.

The type strain, $\mathrm{d} 8-1^{\mathrm{T}}\left(=\mathrm{LMG} 24005^{\mathrm{T}}=\right.$ BCRC $\left.17657^{\mathrm{T}}\right)$, was isolated from a water sample collected from a spring located in Nature Valley, Hsinchu County, Taiwan.

\section{Acknowledgements}

W.-M. C. was supported by grants from the National Science Council, Taipei, Taiwan, Republic of China (NSC 95-2320-B-022-001-MY2 and 95-2313-B-022-001). J.-C.C. was supported by the 21C Frontier program of Microbial Genomics and Applications (grant MG05-01021-0) from the Ministry of Science and Technology, Republic of Korea.

\section{References}

Chen, W. M., Laevens, S., Lee, T. M., Coenye, T., de Vos, P., Mergeay, M. \& Vandamme, P. (2001). Ralstonia taiwanensis sp. nov., isolated from root nodules of Mimosa species and sputum of a cystic fibrosis patient. Int J Syst Evol Microbiol 51, 1729-1735.

Chen, W. M., Moulin, L., Bontemps, C., Vandamme, P., Bena, G. \& Boivin-Masson, C. (2003). Legume symbiotic nitrogen fixation by beta-proteobacteria is widespread in nature. J Bacteriol 185, 7266-7272.

Chung, Y. C., Kobayashi, T., Kanai, H., Akiba, T. \& Kudo, T. (1995). Purification and properties of extracellular amylase from the hyperthermophilic archaeon Thermococccus profundus DT5432. Appl Environ Microbiol 61, 1502-1506.

Elliott, G. N., Chen, W. M., Chou, J. H., Wang, H. C., Sheu, S.-Y., Perin, L., Reis, V. M., Moulin, L., Simon, M. F. \& other authors (2007). Burkholderia phymatum is a highly effective nitrogen-fixing symbiont of Mimosa spp. and fixes nitrogen ex planta. New Phytol 173, 168-180.

Embley, T. M. \& Wait, R. (1994). Structural lipids of eubacteria. In Chemical Methods in Prokaryotic Systematics, pp. 121-161. Edited by M. Goodfellow \& A. G. O’Donnell. Chichester: Wiley.

Ezaki, T., Hashimoto, Y. \& Yabuuchi, E. (1989). Fluorometric deoxyribonucleic acid-deoxyribonucleic acid hybridization in microdilution wells as an alternative to membrane filter hybridization in which radioisotopes are used to determine genetic relatedness among bacterial strains. Int J Syst Bacteriol 39, 224-229.

Felsenstein, J. (1981). Evolutionary trees from DNA sequences: a maximum likelihood approach. J Mol Evol 17, 368-376. 
Gerhardt, P., Murray, R. G. E., Wood, W. A. \& Krieg, N. R. (editors) (1994). Methods for General and Molecular Bacteriology. Washington, DC: American Society for Microbiology.

Hall, T. A. (1999). BIOEDIT: a user-friendly biological sequence alignment editor and analysis program for Windows 95/98/NT. Nucleic Acids Symp Ser 41, 95-98.

Hurek, T., Wagner, B. \& Reinhold-Hurek, B. (1997). Identification of $\mathrm{N}_{2}$-fixing plant- and fungus-associated Azoarcus species by PCR based genomic fingerprints. Appl Environ Microbiol 63, 4331-4339.

Kimura, M. (1983). The Neutral Theory of Molecular Evolution. Cambridge: Cambridge University Press.

Kluge, A. G. \& Farris, F. S. (1969). Quantitative phyletics and the evolution of anurans. Syst Zool 18, 1-32.

Kumar, S., Tamura, K. \& Nei, M. (2004). MEGA3: integrated software for molecular evolutionary genetics analysis and sequence alignment. Brief Bioinform 5, 150-163.

Lanyi, B. (1987). Classical and rapid identification methods for medically important bacteria. Methods Microbiol 19, 1-67.

MacFaddin, J. F. (2000). Biochemical Tests for the Identification of Medical Bacteria, 3rd edn. Baltimore, MD: Williams \& Wilkins.

Mesbah, M., Premachandran, U. \& Whitman, W. B. (1989). Precise measurement of the $\mathrm{G}+\mathrm{C}$ content of deoxyribonucleic acid by high-performance liquid chromatography. Int J Syst Bacteriol 39, 159-167.

Moulin, L., Munive, A., Dreyfus, B. \& Boivin-Masson, C. (2001). Nodulation of legumes by members of the $\beta$-subclass of Proteobacteria. Nature 411, 948-950.

Pot, B., Vandamme, P. \& Kersters, K. (1994). Analysis of electrophoretic whole-organism protein fingerprints. In Chemical Methods in Prokaryotic Systematics, pp. 493-521. Edited by M. Goodfellow \& A. G. O'Donnell. Chichester: Wiley.

Powers, E. M. (1995). Efficacy of the Ryu nonstaining KOH technique for rapidly determining gram reactions of food-borne and waterborne bacteria and yeasts. Appl Environ Microbiol 61, 3756-3758.
Quan, Z. X., Im, W. T. \& Lee, S. T. (2006). Azonexus caeni sp. nov., a denitrifying bacterium isolated from sludge of a wastewater treatment plant. Int J Syst Evol Microbiol 56, 1043-1046.

Reinhold, B., Hurek, T., Niemann, E. G. \& Fendrik, I. (1986). Close association of Azospirillum and diazotrophic rods with different root zones of Kallar grass. Appl Environ Microbiol 52, 520-526.

Reinhold-Hurek, B. \& Hurek, T. (2000). Reassessment of the taxonomic structure of the diazotrophic genus Azoarcus sensu lato and description of three new genera and new species, Azovibrio restrictus gen. nov., sp. nov., Azospira oryzae gen. nov., sp. nov. and Azonexus fungiphilus gen. nov., sp. nov. Int J Syst Evol Microbiol 50, 649-660.

Rosado, A. S., Duarte, G. F., Seldin, L. \& Van Elsas, J. D. (1998). Genetic diversity of nifH gene sequences in Paenibacillus azotofixans strains and soil samples analyzed by denaturing gradient gel electrophoresis of PCR-amplified gene fragments. Appl Environ Microbiol 64, 2770-2779.

Saitou, N. \& Nei, M. (1987). The neighbor-joining method: a new method for constructing phylogenetic trees. Mol Biol Evol 4, 406-425.

Sasser, M. (1990). Identification of bacteria by gas chromatography of cellular fatty acids, MIDI Technical Note 101. Newark, DE: MIDI Inc.

Wayne, L. G., Brenner, D. J., Colwell, R. R., Grimont, P. A. D., Kandler, O., Krichevsky, M. I., Moore, L. H., Moore, W. E. C., Murray, R. G. E. \& other authors (1987). International Committee on Systematic Bacteriology. Report of the ad hoc committee on reconciliation of approaches to bacterial systematics. Int J Syst Bacteriol 37, 463-464.

Xie, C.-H. \& Yokota, A. (2004). Phylogenetic analyses of the nitrogenfixing genus Derxia. J Gen Appl Microbiol 50, 129-135.

Young, J. P. W. (1992). Phylogenetic classification of nitrogen-fixing organisms. In Biological Nitrogen Fixation, pp. 43-86. Edited by G. Stacey, R. H. Burris \& H. J. Evans. New York: Chapman \& Hall.

Zani, S., Mellon, M. T., Collier, J. L. \& Zehr, J. P. (2000). Expression of nifH genes in natural microbial assemblages in Lake George, New York, detected by reverse transcriptase PCR. Appl Environ Microbiol 66, 3119-3124. 